\title{
Factors Affecting the Efficiency and Effectiveness of Reverse Logistics Process
}

Author(s): Gangani Sureka, Yapa Mahinda Bandara, Deepthi Wickramarachchi

Source: Journal of International Logistics and Trade 2018; 16(2):74-87

Published by: Jungseok Research Institute of International Logistics and Trade, Inha University

DOI: https://doi.org/10.24006/jilt.2018.16.2.074

The Journal of International Logistics and Trade is an official journal published by Jungseok Research Institute of International Logistics and Trade, Inha University, Korea. JILT welcomes manuscripts that advance the practice and science of logistics, trade, and other related fields.

Frequency: Quarterly (March, June, September, December)

Stable URL: https://www.ejilt.org

The Jungseok Research Institute of International Logistics and Trade is a specialized academic research institute representing Inha University and the Inha Foundation in Korea. The institute aims to become a representative institute in Northeast Asia in the research of logistics and trade.

Stable URL: https://jrieng.inha.ac.kr

(C) Copyright. Jungseok Research Institute of International Logistics and Trade.

This is an Open-Access article distributed under the terms of the Creative Commons Attribution NonCommercial License (http://creativecommons.org/licenses/by-nc/4.0/) which permits unrestricted noncommercial use, distribution, and reproduction in any medium, provided the original work is properly cited 


\title{
Journal of
}

\section{International Logistics and Trade}

\section{Factors Affecting the Efficiency and Effectiveness of Reverse Logistics Process}

\author{
Gangani Sureka, Yapa Mahinda Bandara*, Deepthi Wickramarachchi \\ Department of Transport and Logistics Management, University of Moratuwa, Moratuwa, Sri Lanka
}

\author{
ARTICLE INFO \\ Article history: \\ Received 17 June 2018 \\ Accepted 31 August 2018 \\ Keywords: \\ Reverse Logistics \\ Soft-drink Industry \\ Returned Empty glass bottles \\ Prominent factors \\ Pareto Analysis \\ Analytical Hierarchy Process.
}

\begin{abstract}
The purpose of this research is to identify the current reverse logistics practices adopted by soft drink companies and the prominent factors which can decide the efficiency and effectiveness of the entire process of the reverse logistics channel. The paper employs Pareto analysis and the Analytical Hierarchy Process (AHP) method on data collected from logistics professionals involved in the software industry in Sri Lanka using two questionnaires. As the prominent factors, transportation, accidents, packaging, a method of storage, the cleaning process and sorting process was identified and the first four prominent factors have a higher influence on both measures of efficiency and effectiveness. They can also identify the external factors which can emerge inefficiencies due to outsourced dealers. Lack of previous literature on the subject matter and the difficulty to access the filed data were the main limitations of this study. The identified factors will help to identify the correct root causes for the inefficiencies of the current reverse logistics practices and concentrating on these factors will give an opportunity for the soft drink industry players to successfully implement a sustainable green supply chain which reduces waste at each stage of its forwards and reverse logistics process. Transportation, Accidents, Packaging, and Storage have been previously identified as considerations in reverse logistics processes and the current study showed that they have a higher impact on both efficiency and effectiveness on reverse logistics and these factors should be given specific consideration while in the operations.
\end{abstract}

\section{Introduction}

Increasing efficiency in reverse logistics processes such as the recovery of the returned products or disposal of endof-life products is one way in which firms attempt to maintain and increase competitiveness and market share (Huscroft, et al. 2013). To strategize cost-efficient product, take-back plan, there has been growing interest in the development of reverse logistics that drives the reverse flow of returned products from the end customers back to the original equipment manufacturers (Kim 2009). The redesign of the supply chain to effectively handle product returns is important to be capable of remanufacturing, recycle or waste disposal. Identifying the factors that affect an effective and an efficient reverse logistics process can be useful for the overall industry efficiency (Venkatesh et al. 2015). Structured analysis on the selected factors can add value to reverse logistic partner selection process and these factors can be coupled with operation research techniques to improve the performance of the business as well as to identify the area of Improvement. Maintaining an effective and efficient reverse logistics process has moved to the forefront as a key capability for logistics and manufacturing firms (Huscroft et al. 2013). The primary reason for the high focus on the reverse logistics of manufacturers is that it can lead to saving up to $60 \%$ of the estimated cost of a completely new product (Grabara et al. 2014).

Generally having a well-managed efficient and effective reverse channel can result in many direct and indirect benefits

\footnotetext{
* Corresponding author: Department of Transport and Logistics Management, University of Moratuwa, Moratuwa, Sri Lanka Email: mahindayb1977@gmail.com
} 
to any business organization. Reverse logistics mainly consist of three driving forces such as economic value proposition, legislation, and corporate citizenship. Economically a well-managed reverse logistics program can bring direct gains such as input material, cost reduction, and value-added recovery and indirect gains like impending legislation, market protection, green image, improved supplier and customer relations (Dekker et al. 2004). Reverse logistics activities can include disposition determination, recycling, remanufacturing, disposal, resale, warehousing, or transportation; depending on the type of product or material being returned (Huscroft et al. 2013). A related definition of reverse logistics emphasizes both the focus of reverse logistics on the backward flow of materials from customer to supplier and the goals of maximizing value from the returned item or assuring its proper disposal (Rogers and Tibben-Lembke 1999). A highly competitive industry like soft drinks manufacturing and distribution having an efficient and effective reverse logistics process can create a competitive advantage over its competitors by being able to reduce the total logistics cost through the optimum usage of returned empty glass bottles at the right time. Most importantly this can give a higher achievement in sustainability goals of the manufacturing company by the better disposal of empty bottles after its usable lifetime. Adding to that an efficient and an effective reverse logistics channel can improve the reverse supply chain visibility while increasing productivity and greater responsiveness in the entire supply chain. Thus, the main objectives of this research are to identify current reverse logistic practices adopted by soft drink manufacturing companies in Sri Lanka and investigate into the critical factors that affect the efficient and effective functioning of reverse logistics of empty soft drink glass bottles.

This paper will provide an insight into the current reverse logistics model adopted by soft drink manufacturing companies in Sri Lanka while identifying the most critical factors that influence an efficient and effective reverse logistics system. The paper is organized as follows. Next Section carried out a comprehensive literature review on reverse logistics practices and models discussed in scholarly work. Section 3 presents the methodology used in this paper. Section 4 presents the soft drink industry in Sri Lanka as a background. Section 5 is the data analysis and results and conclusions are in Section 6.

\section{Literature review}

Scholarly research on the mainstream supply chain management has much focus on reverse logistics and there is a growing recognition of reverse logistics as a driver of supply chain and logistics (Pokharel and Mutha, 2009). Jian-Jun et al. (2017) carried out an extensive review of reverse logistics research and showed that different methodologies have been used to study reverse logistics processes of different studies. For an industry like soft drinks manufacturing, which is highly competitive, the logistics process acts a vital role. Fragile nature of the product container, glass bottles, makes the reverse logistics process more cumbersome as they are prone to get damaged due to loading, handling, transporting and storing. Since there are many competitors trying to increase their market share in the soft drink industry, it is always required to place the right product in the right place at the right time (Kumarasiri and Arunathilake 2016). Due to the lack of a framework to access RL network and more attention on the forward distribution, Soft-drink manufacturers are bearing a high rate of inefficiencies and ineffectiveness within the backward chain (Umer and Afzal 2012). For the Soft Drink industry, the main customer would be distributor agents from the manufacturer's point of view. Soft drink industry operates with indirect distribution channels other than direct sales channels by manufacturers due to high overheads. As a result, the outbound logistics of the soft drink industry is handled by outsourced dealers (Kumarasiri and Arunathilake, 2016; Umer and Afzal, 2012).

Extant literature has more focused on developing quantitative models to design reverse logistics processes. For example, Fleischmann et al. (1997) presented a more general framework for reverse logistics of soft drink returnable bottles by taking in to account three main areas of the process, namely distribution planning, inventory control, and production planning.

Efficient planning and execution of reverse logistics would provide firms a competitive edge in the development of sustainable, yet profit-generating, business strategies (Kim 2009). Containers, packaging and refillable bottles are typically items, which can be re-used without much work (Lee et al. 2002). After treatment retrieval of empty bottles known as 'return glass bottles' (RGB), which is a major part in reverse logistics of soft drink bottling industry. Nevertheless, companies were so long under the impression that returns compared to sales generate little or no money (Umer and Afzal 2012).

In a centralized distributional system, all products of the reverse logistics pipeline are brought to a central facility, where they are sorted, processes, and then shipped to their next destinations (Reddy 2011). While stores and depots may keep a minimum portion of the deposit to compensate themselves for handling and storage costs, most stores fully refund the deposit to customers. Soft-drink bottlers keep the unredeemed deposits, which compensate them for unreturned bottles (Umer and Afzal 2012) The possible penalties for not adequately addressing the reverse logistics needs of the firm could be increased transportation costs, increased inventory and warehousing costs, increased repair costs of returned products, and lost the secondary value of defective products or materials due to processing delays in the reverse logistics process (Huscroft et al. 2013).

From the investigation of factors influencing the perceptions of cooperative-like franchise practices, it is seen that 
cooperation brings more benefits and organization than non-franchise activities in reverse logistics practices. Firms should improve worker skills, technology and economies of scale through training, cooperation and development of information systems. Improvement in the reverse logistics practices can sustain recycling activities, as well as training programs for reverse logistics experts and supportive policies from the government to enhance recycling practices in the country (Pumpinyo and Nitivattananon 2014). Jian-Jun et al. (2017) showed that there is a lack of operational and strategic areas in reverse logistics research. Each definition on reverse logistic has considered the two specific aspects of "efficient" and "effective" flow of the material that is passing through the backward chain. Thus, it is evident that the backward flow needs to manage properly to achieve those specific performances. Unless firms identify the factors that can affect the efficiency and effectiveness of product flow it is hard to manage it in a better way. From the numerous factors that can hinder or boost the efficient and effective flow of reverse logistics, it is very important to identify the most critical factors.

Bahiraei et al. (2015) investigated critical success factors based on supply chain management perspective and found that transportation as the most important factor followed by process planning and resource efficiency while innovation was ranked the lowest. In the same manner, Mangla et al. (2016) studied critical success factors contributing to successful implementation of reverse logistics and found that the global competitiveness as the main factor while regulatory, human resource, organizational factors, economic factors and strategic factors are ranked respectively. Similar results are observed in the work done by Agrawal et al. (2016). In a different context, availability of in-house expert and trained personnel, customer satisfaction, the flexibility of the system, a financial advocate of managers and flexibility of management are a major strength in the implementation of reverse logistics (Ganjali et al. 2016).

The reverse logistics of beverage containers entails collaborative efforts of all stakeholders and supply chain actors. Any market lacking supply chain cooperation will give room for inefficiencies in the system. Therefore "there is a need for a comprehensive study on reverse logistics and the supply chain of beverage containers in developing countries (Dudubo 2017). In addition, identifying the parameters which can have an impact on the efficiency and effectiveness of the reverse channel is important. The agreement and regulations by the government also influence the success of reverse logistics practices and in addition, internal and external barriers must be slowly overcome and eliminate it. The successful of reverse logistics in foods and beverage industries not only give benefits to the organization in terms of costs or profits but mainly benefits to environmental impacts (Ngadiman et al. 2016). However, the internal and external barriers are not clearly identified as per their criticalness.

Based on the defined hierarchy of reverse logistics or the $3 \mathrm{R}$ concept (reduce, reuse and recycle), most of the literature focus on reduction and recycling or waste management, yet there is a significant impact on reusing the feasible products, if examine the parameters which need to be addressed for an efficient and effective reverse handling to make them reusable in the context of Sri Lankan Soft Drink industry. While the mainstream literature mainly centers on critical success factors influential to the implementation of reverse logistics, there is a gap in reverse logistics research on critical success factors in the operation of reverse logistics process, which this paper attempts to address.

Many kinds of literature are found regarding reverse logistics quantitative models for distribution management under different industry segments. Few published research studies were found regarding reverse logistics of soft drink industry in developing country context. As reverse logistics is a very broad area expanding for many directions under different industry segments or activities, it has been showed that reverse logistic activities can include disposition determination, recycling, remanufacturing, disposal, resale, warehousing, or transportation; depending on the type of product or material being returned (Huscroft 2010). Because of this vast diversification of this research area, most of the literature was found in generic settings or targeting several industry segments like automobile, electronics, computer, FMCG. Therefore, a study focusing on the soft drink industry of Sri Lanka was selected as the focus area due to the prevailing gap identified in this field of study. The population of this study was narrowed down to address the exact problem of this industry. The topic and scope narrow down in this research can be illustrated as follows (Figure 1).

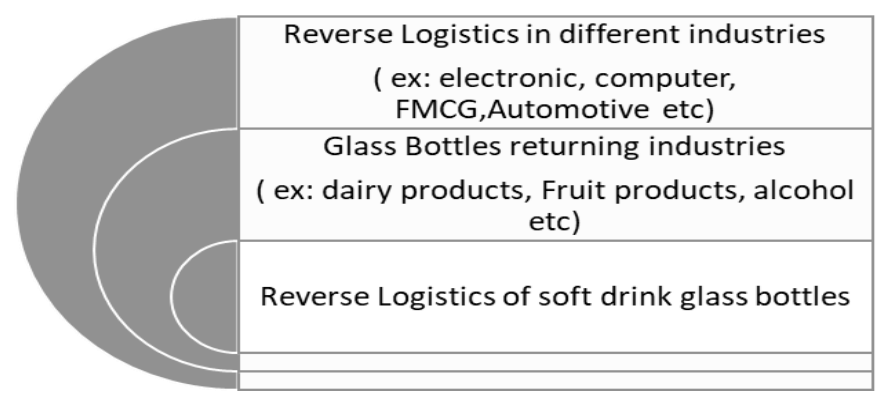

Figure 1. Research sample and scope

Reverse logistics process is practiced in many industries in the world and Sri Lanka as well. A related definition of reverse logistics emphasizes both the focus of reverse logistics on the backward flow of materials from customer to supplier and the goals of maximizing value from the returned item or assuring its proper disposal (Rogers and TibbenLembke 1999). The purpose of the product return can be varied based on the type of industry such as return to supplier, 
re-sell, sell via an outlet, salvage, recondition, refurbish, remanufacture, reclaim materials, recycle, or landfill. If the returning is a packaging it can be for reuse, refurbish, reclaim materials, recycle, or salvage. In this research, the selection of the population is based on the industry which falls under the category of package returning for reusing for remanufacturing the product. But If we consider this category again there are a number of players fallen under this category based on the type of product carries in the glass bottle or the packaging. Those can be dairy product manufacturers, fruit drink manufactures, alcohol manufacturers etc. Thus, to be more specific in the research and to find exact results for the identified problem the population was narrowed down to companies manufacturing soft drink or carbonated, non-alcoholic beverages in glass bottles.

\section{Methodology}

\subsection{Sample and population}

The unit of this study is the reverse logistics processes of soft drink manufacturing firms. There are four main soft drink manufacturers or carbonated beverage manufactures in Sri Lanka. Out of the four, only three manufacturers are producing soft drinks in glass bottles and the other one is doing only plastic bottle manufacturing. Among these three, two are representing their respective companies, while the third one is having a joint production of different brands. The population of this research is the total number of distributors representing soft drink manufacturing companies' and their transportation a distribution function.

Since the population of this study is small, the data collection was done covering all three players in this industry. The questionnaires of each stage were sent to all three soft drink manufacturers. Since the distributors of each manufacturer are only handling the transportation and outbound logistics function and as they are not responsible for any other means they were not considered under the population or sample.

\subsection{Data collection sources and methods}

Questionnaire surveys and interviews were used as the primary data collection methods. An online questionnaire and an emailed questionnaire were used to collect primary data to identify prominent factors and descriptive details about the industry. In person and telephone interviews were conducted with the intention of obtaining further information regarding critical factors and gather primary data to weight each critical factor. As secondary data collection, past research was reviewed to find important criteria for efficient and effective reverse logistics in the soft drink industry, within past two decades and the most influential criteria for this aspect was selected. The method used to calculate the respective weights for prominent criteria was based on the Analytical Hierarchy Process method. Data collection was carried out in three stages (Table 1).

Table 1. Data collection details

\begin{tabular}{|c|c|c|c|}
\hline \multirow{2}{*}{ Data collection stage } & \multicolumn{3}{|c|}{ Data collection } \\
\hline & Method & Number of responses & Valid Responses \\
\hline Stage 1 & Quantitative data survey & 1 & 1 \\
\hline Stage 2 & Questionnaire Survey (Factor Identification) & 9 & 9 \\
\hline Stage 3 & Questionnaire survey for AHP (weight calculation) & 5 & 5 \\
\hline
\end{tabular}

At stage one, using the first questionnaire, numerical data regarding the number of soft drink cases issued to five dealers and returned by them to the manufacturer for twelve months a year were collected. These data were used only to diagnose the existing problem of the mismatch between the issued number of glass bottles and returns to prove the hypothetical problem.

At stage two, a questionnaire was developed using a thorough literature survey. Thirteen factors were identified and included in this questionnaire to derive the relative importance of each factor for efficient and effective reverse logistics process. These factors are transportation, a method of storage, packaging, sorting process, a cleaning process, shelf life, demand fluctuations, lifespan of the product, usage pattern, consumption method, intermediate HR involvement, accidents, and information.

Transportation: This is the most vital activity which can be observed by all parties in the supply chain. Back-loading refers to the use of vehicles to carry loads on the return legs of delivery journeys, with the aims of increasing vehicle utilization and improving transport efficiency (McLeod et al. 2008). It has been argued that although reverse logisticsrelated transportation costs can decline due to consolidation, handling transportation in a centralized system might increase the cost but not the revenue. It is mentioned that 'if a product is going to be thrown away, transporting it to a centralized facility just to throw it away increases costs, but does not increase revenues, because the product is still thrown away' (Rogers and Tibben-Lembke 2001).

Method of storage: Storage aspect is concerned mostly with the Retailers, distributors, and manufacturers in the supply 
chain. These stakeholders strive to design a reverse logistics system which can increase the visibility as well as the speed of the return process in order to maximize recovery. Seasonal or short lifecycle products are critical in this aspect since efficient return and reprocessing is very valuable. Different storage methods can be adopted by the manufacturers and distributors while the product is in transit to the consumer. Mostly preferred storage methods at warehouses for Soft Drink glass bottles are block stacking and some preferred palletized cargo for easy handling purpose. In addition to the expert opinions this criterion was identified through the observation at random visits to soft drink distributor locations in the Colombo area.

Packaging: In the soft drink Industry, especially in glass bottle manufacturers, there are two types of packaging. The empty soft drink glass bottle itself is the packaging for the soft drink product and twelve or sixteen products are packed in a packaging made up of plastic or steel. These two types are the material that flows in both the forward and reverses channel of the supply chain. The empty soft drink glass bottle falls in to end of use return case category. This criterion was mainly highlighted by the operation mangers and production executives in the soft drink industry when discussing regarding the factors to be considered in this study.

Accidents: This aspect includes an accident that can happen while products had been transported throughout the distribution channel. This can basically include any type of accident even at the loading and unloading process as well. This can be basically while in transit due to the underutilized capacity of the vehicle or not using appropriate vehicles for distributing. Industry experts suggested that even though there is a less probability of occurrence the impacts of an accident can have a severe impact which can't recover any losses.

Cleaning process: This process is conducted within the processing center. Cleaning of the used empty soft drink glass bottles is one of the crucial factors due to a large input of labor, time and technology. This process can have severe impacts on the effectiveness of the empty bottles even though it is the last stage before refilling.

Sorting process: Mostly sorting process of all products for the reverse logistics done after bringing to a central facility, where they are sorted, processed, and then shipped to their next destinations. It has been described as 'One of the most important activities is the sorting step employees make decisions about whether the product can be resold or if it has to be scrapped. Obviously, determining the best channel for re-positioning of the product is of critical importance in maximizing revenue from the products in the reverse logistics pipeline' (Rogers and Tibben-Lembke 2001).

Information: Lack of information about the process is one of the biggest challenges facing firms dealing with reverse logistics (Rogers and Tibben-Lembke 2001). It has also highlighted that 'Poor data collection leads to uncertainty about return causes. In the long run, the most valuable outcome of sound reverse logistics management is the accumulation of data. Improving the return process and efficiently handling the returned products decreases costs. Those firms that manage information well also manage their inventories effectively. Those that do not manage well the data surrounding their logistics processes do not generally manage their inventories effectively; This same rule applies to reverse logistics as well (Rogers and Tibben-Lembke 2001).

Shelf life: Shelf life is the recommendation of time that products can be stored, during which the defined quality of a specified proportion of the goods remains acceptable under expected (or specified) conditions of distribution, storage, and display. The length of the product life cycle varies across products and industries (Rogers and Tibben-Lembke 2001). All products have a different lifespan, for example, an item of "trendy" clothing will have a very short lifespan, while other products may have a very long lifespan. In this variable, we will see what lifespan of the soft-drink product is and how the lifespan of product effects on reverse logistics process.

Demand fluctuations: The demand fluctuations are another main factor which decides the efficient and effective reverse logistics. It has explained that 'the expansion of many small, manual separation centers affected market share, as they have to compete against each other in recyclable material pricing, leading to reduced production if investment in the expansion was not sufficient at a particular time (Pumpinyo and Nitivattananon 2014).

Intermediate human resource involvement: It has been discussed by Pumpinyo and Nitivattananon (2014) that there are seven main barriers affecting for reverse logistics of the business that includes financial difficulty, market competitiveness, managerial issues, and labor concerns. There were always only temporary workers due to the type of hard work and the unfavorable working environment (working in a dirty place and with odors). Lacking permanent labor leads to a lack of well-trained and skilled workers, which ultimately causes the instability in a number of companies. Labor concerns: there were always only temporary workers due to the type of hard work and the unfavorable working environment (working in a dirty place and with odors). Lacking permanent labor leads to a lack of well-trained and skilled workers, which ultimately causes the instability in a number of companies.

Product lifespan: Since it is not easy to identify where a real product is in the life cycle once it moves past the introductory and growth stages, every firm must look for demand turning points. These can be seen if the company understands history and the marketplace and will allow the firm to understand the expected behavior for the volume of units returned through its RL system competitive environments have caused the product lifecycle for many consumer goods to continually shrink (Guide and Wassenhove 2003).

Consumption method: This factor basically addresses the issues faced by the manufacturers when cleaning the bottle due to various methods, conditions and habits of end users or the customers. Many industry experts explained some consumers insert the straws into the bottle and some are contaminated with cement and concrete after using them at construction sites which need an extra effort, time and money for reclaiming the bottle to a reusable level. Due to poor 
handling, malfunctioning opening cutters and storage, the glass bottle edges near the lid are damaged which make it inappropriate to use. This criterion was identified through industry expert opinions in the discussions held at the initial stage of the data collection process. Thus, this can be considered as primary data which was identified in the preliminary stage of this study.

Usage pattern: The pattern of usage by the customer or end user can affect to the efficiency of reverse logistics. It has suggested that the product use pattern, with respect to location, intensity, and duration of use, is an important group of characteristics as it affects, for instance, the collection phase. It will make a difference whether the end user is an individual or an institution (bulk-use), demanding different locations for collection or different degrees of effort from the end-user (e.g. bringing it to a collection point) Time is not the only component describing intensity of use, but also the degree of consumption during use (Dekker et al. 2004).

At stage three, a questionnaire was used to carry out the factor comparison for AHP analysis and to find the influence level of each factor for two measures of reverse logistics, the efficiency, and effectiveness. The following hierarchy was used (Figure 2).

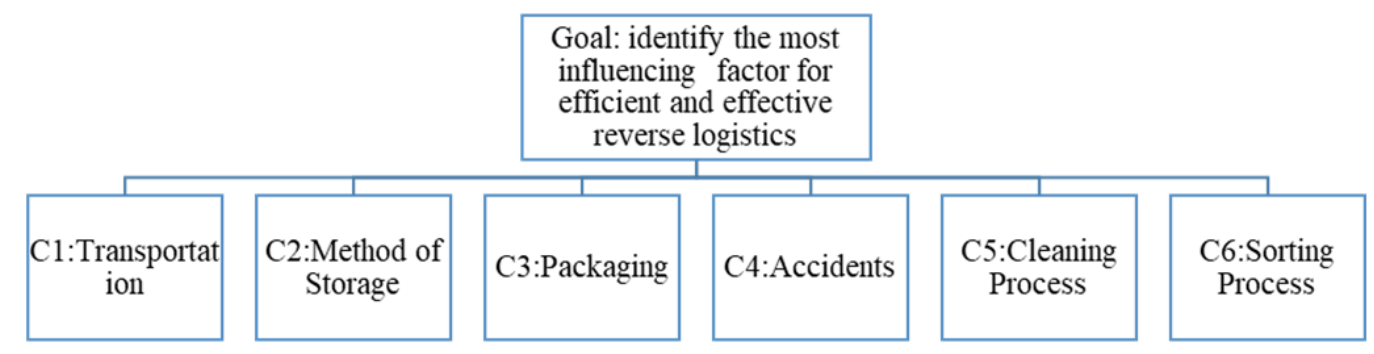

Figure 2. Factor hierarchy measuring the effectiveness of the reverse logistics process

\subsection{Data analysis method}

To find and rank critical success factors there are several approached used in literature. The Technique for Order of Preference by Similarity to Ideal Solution (TOPSIS), a multi-criteria decision-making method, is used by Agrawal et al. (2016); Bahiraei et al. (2015). Further, a structural model is proposed by Mangla et al. (2016) using Analytical Hierarchy Process (AHP) and Decision Making Trial and Evaluation Laboratory (DEMATEL) methods to evaluate the critical success factors contributing to the implementation of a reverse logistics process. This paper uses descriptive analysis and factor ranking calculation using Pareto analysis using Microsoft Excel to identify main factors influential to the operation of reverse logistics process. Next, Analytical Hierarchical Process method was used to calculate the weights for each factor and identify the most prominent factor impacting the operation of reverse logistics process.

\section{Sri Lankan soft drink industry}

The industry sector of Sri Lanka accounts for 27.1\% of the GDP 2016. (Economic Statistics of Sri Lanka 2016) and sub division, beverages represents for $8.1 \%$ of the composition of factory industry production index which is a significant value. (Annual Report 2016)

In the soft drink industry, the model adopted by the manufacturers for distribution of products is that handling the outbound logistics of the soft drink bottles is outsourced distributing agents or distributors from covering all areas of the country. The distributors distribute the soft drinks packed as cases to the retailers and collect empty bottles from them in their return trip. A deposit settling method is adopted throughout the forward and reverse logistics of the supply chain. The pilot survey of this research found that there are a limited number of agencies who operate in large scale and handle distribution of one or two manufacturers. But these distributors do not maintain long-term databases regarding the number of bottles distributed in the forward and reverse channel.

There are four soft drink manufacturing companies in Sri Lanka. Out of the four players in nonalcoholic beverage sector three of the manufactures are producing carbonated soft drinks in glass bottles with the cumulative market shares of $93 \%$ of the Soft Drink Industry of Sri Lanka. Referring to figure number 3, manufacture 1 account for $43 \%$ of the market share, while manufacture 2 with $40 \%$ and $10 \%$ by the third manufacturer. The remaining $7 \%$ of the market share is owned by the other player, focused only on manufacturing soft drinks with pet bottles.

Following points define the major characteristics of the considered population in this research:

- All three manufacturers do not handle the outbound logistics or the distribution of soft drinks.

- They used outsourced dealers, distributors, or agencies to handle distribution.

- These distributors do not keep long-term data regarding volume of in and out bottles.

- They only do the transportation function. 
- The manufacturers maintain long-term databases regarding the number of bottles given to the distributors and number of bottles distributors return to them.

- All manufacturers of soft drinks are using return glass bottles for remanufacturing purpose and all have outsourced the distribution channel to distributing dealers or third-party logistics providers.

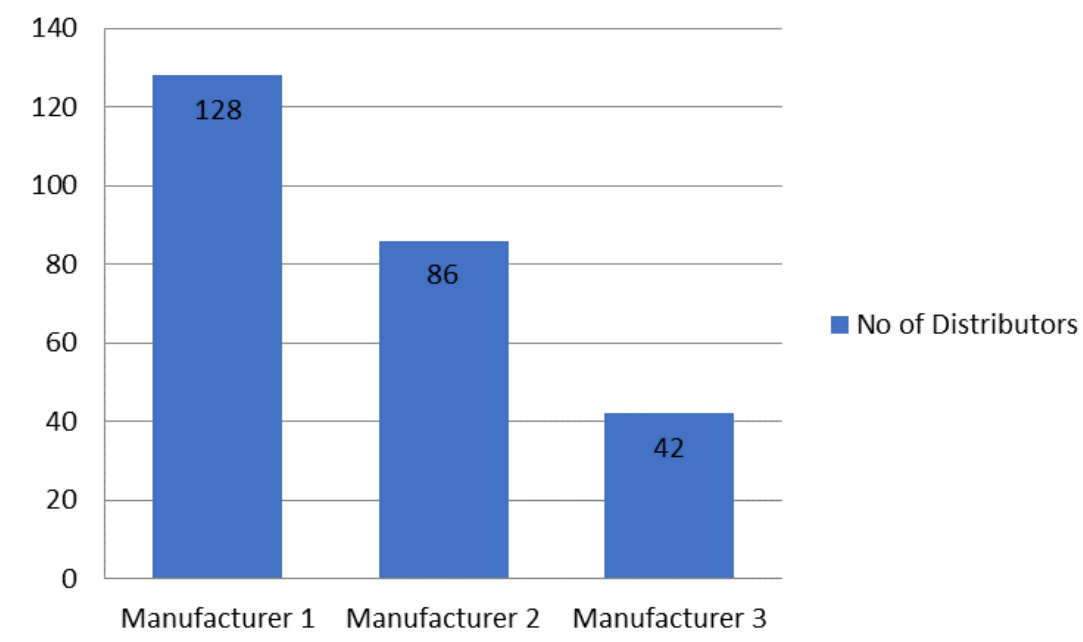

Figure 3. Number of distributors for each soft drink manufacturer

The dispersion of the number of distributors own by each key player in the soft drink industry is shown in Figure 3. Altogether 256 outsourced distributors are handling country-wide distribution of soft drink glass bottles and handle the reverse logistics operations of an empty soft drink glass. A pilot survey with industry experts revealed that the procurement cost of new glass bottles will be $0-20 \%$ of the total production cost. Since the manufacturing companies were not willing to share the confidential financial data, the figures were requested using percentages. According to the pilot survey findings, $56 \%$ suggest one undamaged glass bottle can be used for 1-5 times for refilling, while the rest $44 \%$ suggests that it can be used for more than 1-5 but less than 10 times. The respondents have mentioned that the requirement for procuring new glass bottles for production can depend on the number of damaged bottles and sales plan.

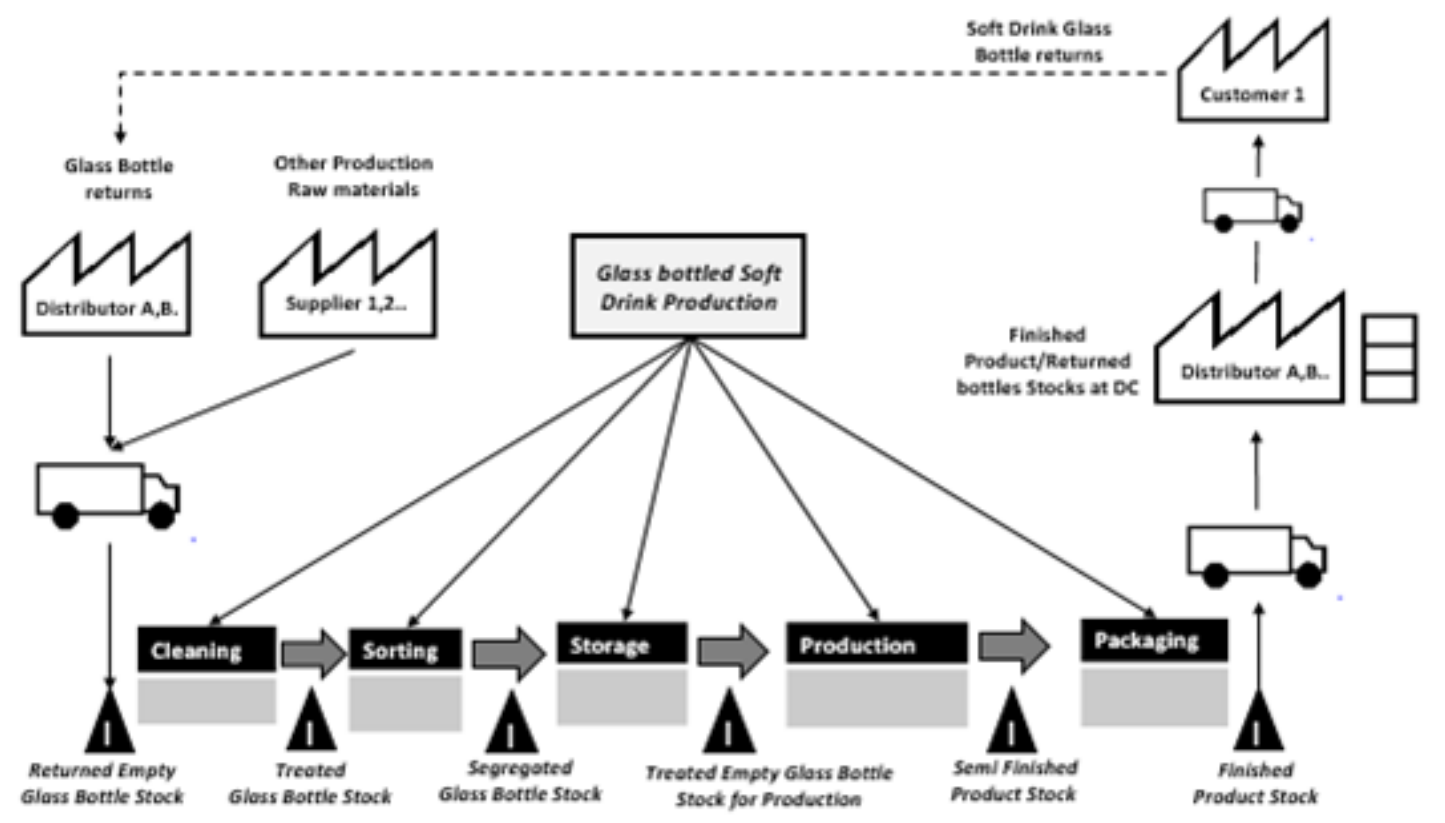

Figure 4. Illustration of reverse logistics channel of soft drink glass bottles in Sri Lanka

The distributing agents collect filled soft drink glass bottles from the manufacturers keeping the refundable deposit, on a pre-planned schedule of the month. While conducting the forward logistics, empty bottles are collected from each retail points and bring to the distributors temporary distributing center. According to the distribution schedule, all distributors carry empty bottles which have collected on the next visit to the manufacturer for the next distribution schedule. The manufacturer keeps all records including a number of bottles received and issued. Empty bottles are sent 
to the processing center and stores after that in the empty bottle storage. This is the model adopted by the Sri Lankan soft drink manufacturers, for the reverse logistic channel of the soft drink industry in Sri Lanka (Figure 4).

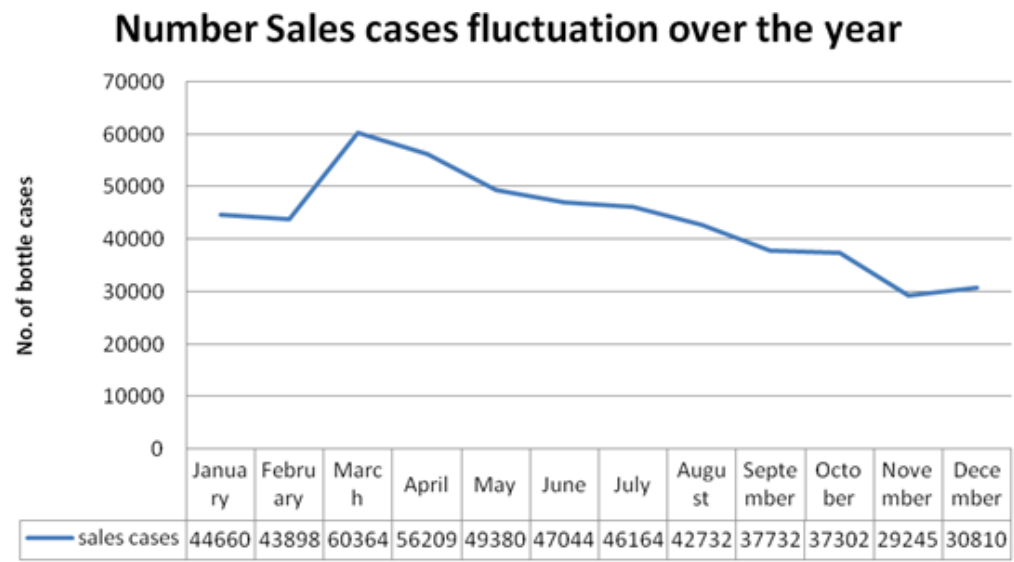

Figure 5. Monthly dispersion of issued soft drink glass bottle cases

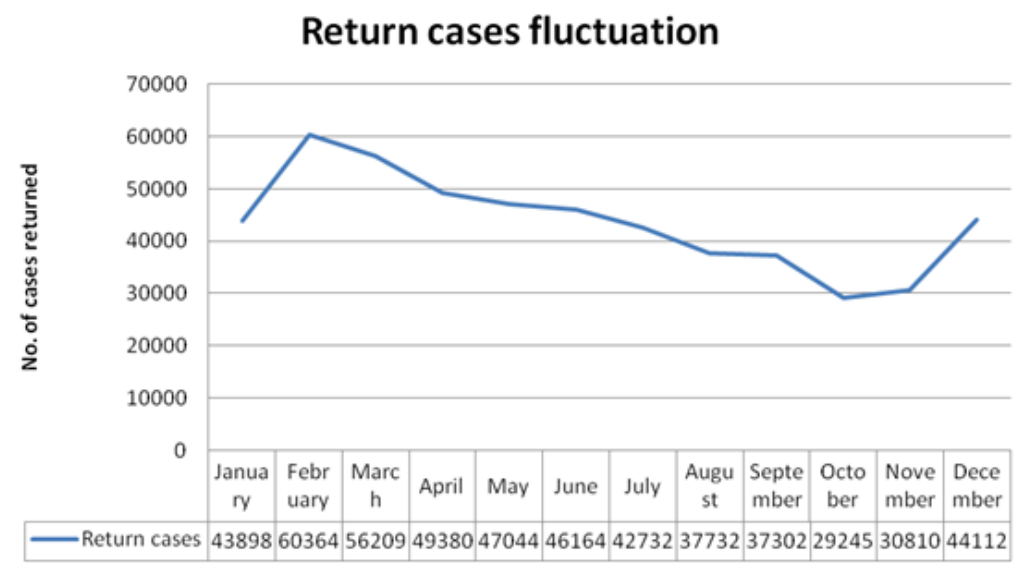

Figure 6. Variation of return volume of bottles over a year

\section{Data analysis and discussion}

\subsection{Problem diagnosis}

Figure 5 shows the variation of the bottle cases issued to five different distributors of one soft drink glass bottle manufacturer. These variations occur based on seasonal demand fluctuations and the sales plan. Technically the returning empty bottles need to be lower or equal to the volume issued in a previous month.

When analyzing the returning numbers as shown in Figure 5 and 6 , it shows that returning volumes are below or higher than the issued volume of bottles in the previous month. This clearly emphasizes that there is no direct relationship between the issued and received and those two are independent. This situation occurs due to various factors. Figure 7 shows that there is an increasing trend in the gap of bottles between issued and received over the year.

\subsection{Descriptive analysis of the soft drink industry}

Out of the total population of leading soft drink manufacturers in Sri Lanka, 75\% of them operate reverse logistics of empty soft drink glass bottles. All are using return glass bottles for re-manufacturing purpose and all have outsourced the distribution channel to distributing dealers or third-party logistics providers. For the main three manufacturers altogether 256 outsourced distributors are handling countrywide distribution of soft drink glass bottles and handle the reverse logistics operations of empty soft drink glass bottles. The industry norm is that if the monthly production cost is $100 \%$ then the procurement cost of new glass bottles will be $0-20 \%$. Out of the total responses, $56 \%$ of the respondents have suggested that one undamaged glass bottle can be used for 1-5 times for refilling, while the rest $44 \%$ suggests that it can be used for more than 1-5 but less than 10 times. The average number of glass bottle requirement per month depends on the number of damaged bottles and the sales plan. 




Figure 7. Trend analysis of the bottle cases gap

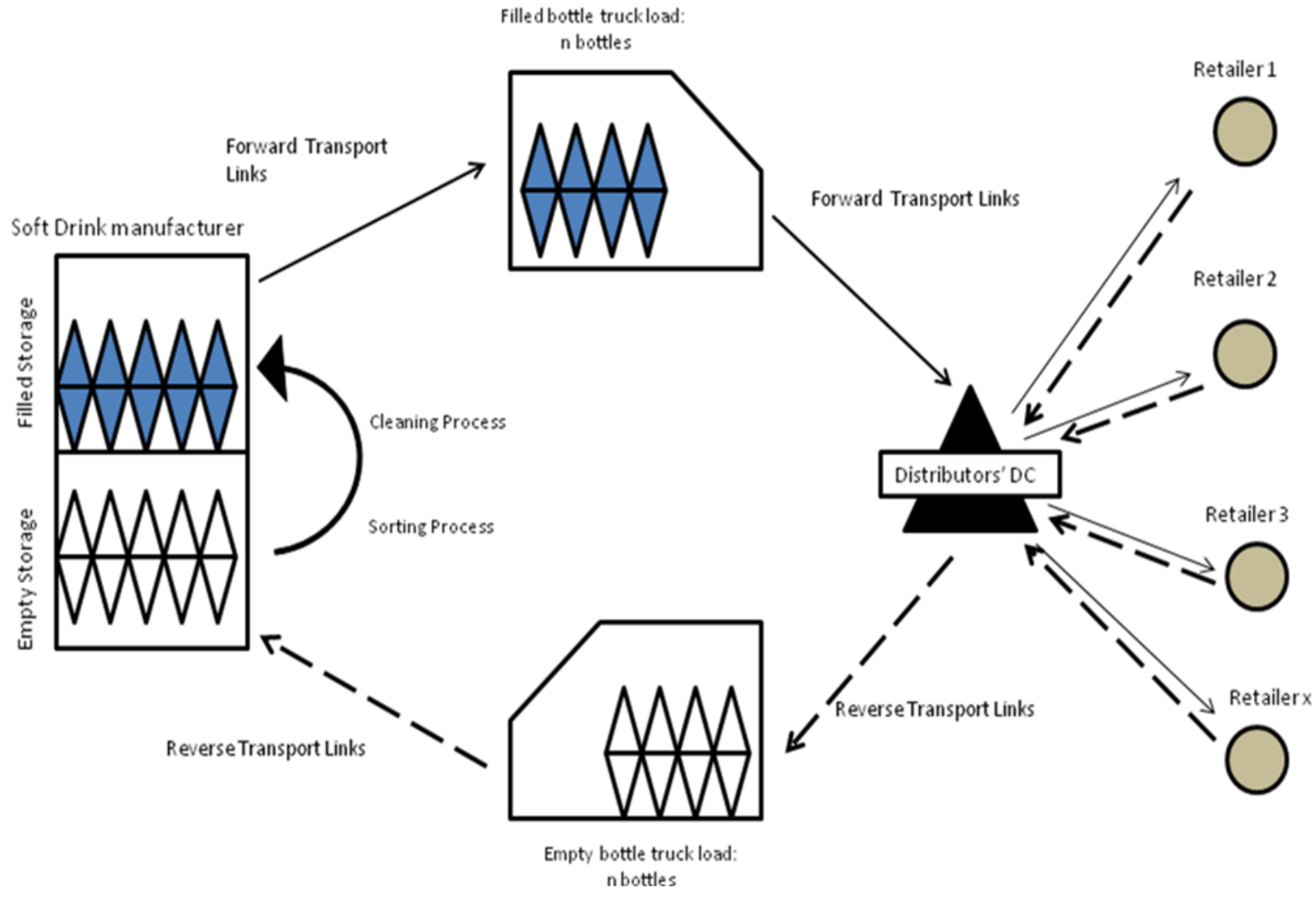

Figure 8. Illustration of the current reverse logistic model for one distributor operation

Figure 8 is an illustration of the current logistics and reverse logistics model operate in the soft drink industry in Sri Lanka developed based on the collected data.

\subsection{Prominent criteria analysis}

As defined in the Pareto analysis, $80 \%$ of the impact is caused by $20 \%$ of the criteria. It was found from the Table 2 and the Figure 9 that $80 \%$ of the impact is due to 10 factors out of 13 factors identified from the literature survey. Since there can be some other factors which can have a minor impact, but not included in the identified criteria list, 10 factors could be the $20 \%$ of the total number. As the most important criteria and to reduce the complexity of the pairwise comparison proceedings and also to ensure the accuracy of pairwise comparison, the topmost six factors were selected. These include Transportation, Method of Storage, Packaging, Accidents, cleaning process and Sorting process respectively. 
Next, weight calculation using AHP generated factor scores for each factor. Based on the calculations most critical factors are Transportation, Accidents, Packaging, a method of storage, a cleaning process, and sorting process with respective weights of $0.43,0.26,0.14,0.08,0.05$ and 0.04 respectively. The consistency ratio is 0.07 since it is less than 0.1 the data received for calculation of weights are consistent. Further, the level of influence of factors on efficiency and effectiveness derived from AHP analysis is presented in Table 3.

Table 2. Calculation for Pareto analysis

\begin{tabular}{|c|c|c|c|}
\hline Factor & Total Score & Cumulative score & Cumulative $\%$ \\
\hline Transportation & 74 & 74 & 8.60 \\
\hline Method of storage & 73 & 147 & 17.09 \\
\hline Packaging & 71 & 218 & 25.35 \\
\hline Accidents & 70 & 288 & 33.49 \\
\hline Cleaning Process & 69 & 357 & 41.51 \\
\hline Sorting process & 68 & 425 & 49.42 \\
\hline Information & 67 & 492 & 57.21 \\
\hline Shelf life & 63 & 555 & 64.53 \\
\hline Demand Fluctuations & 63 & 618 & 71.86 \\
\hline Intermediate HR Involvement & 62 & 680 & 79.07 \\
\hline Product lifespan & 61 & 741 & 86.16 \\
\hline Consumption method & 61 & 802 & 93.26 \\
\hline \multirow[t]{2}{*}{ usage pattern } & 60 & 862 & 100.23 \\
\hline & 862 & & \\
\hline
\end{tabular}

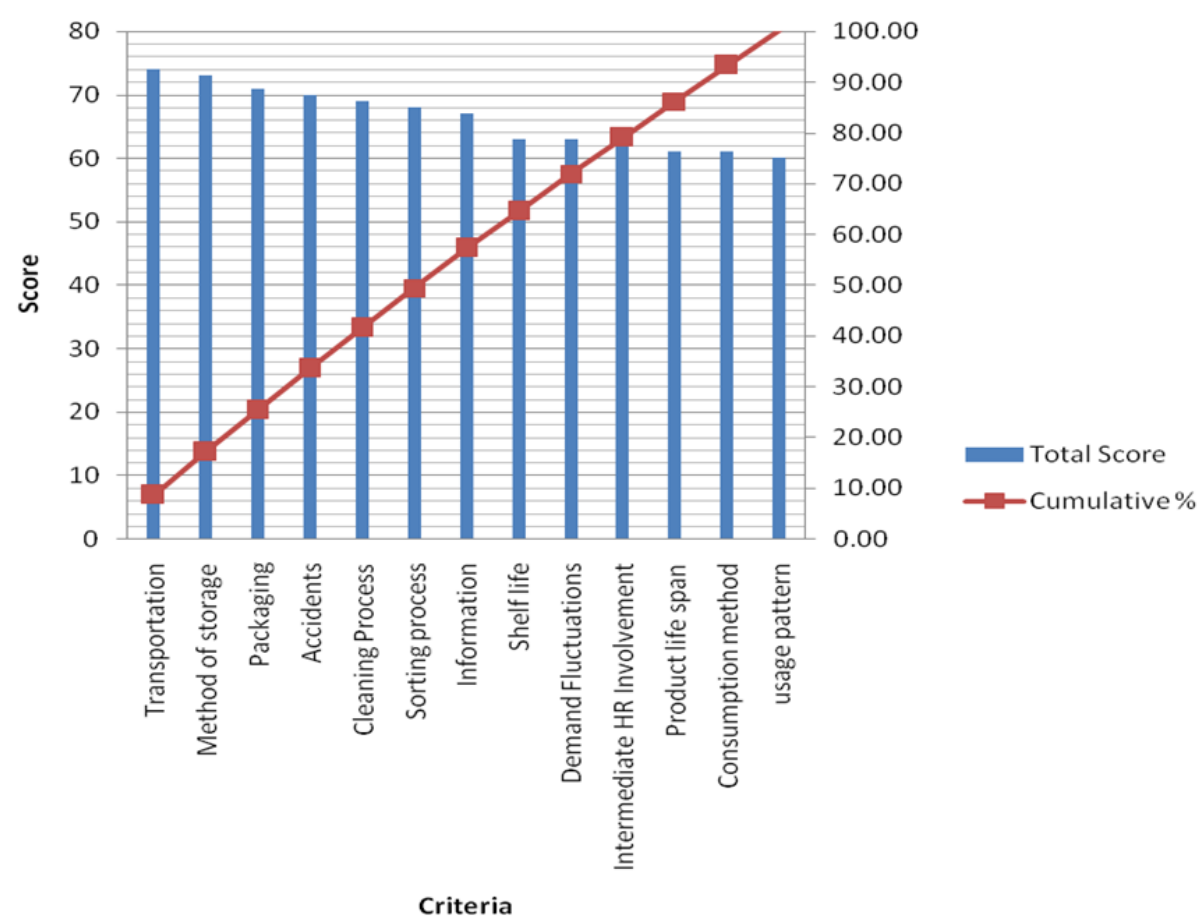

Figure 9. Pareto analysis chart

Most prominent factors identified were Transportation, Accidents, Packaging, Method of Storage, a cleaning process, and sorting process with the respective weights of $0.43,0.26,0.14,0.08,0.05$ and 0.04 . The responses received were consistent with the acceptable level. The factors with higher weight show the criticality of that factor to reverse logistics while those are also having a higher influence on both efficiency and effectiveness of the reverse logistics process. Apart from transportation, factors like accidents, packaging, and method of storage have a higher impactful probability for both measures (Figure 10). Transportation of soft drink bottles mainly planned as a forward flow driven and the empty bottles are collected along with the delivery (Bloemhof-Ruwaard et al. 1999). Among the impacting probability of the most critical factor to two measures, transportation seems to be distributed in a dispersed manner. Transportation has received low response rate that it affects for both efficiency and effectiveness of reverse logistics because, the factor transportation stands for a bigger scope covering numerous subfactors that can be included within it such as driving skill and behavior, vehicle condition, road condition, geographic features of the road, fuel efficiency of the vehicle, road congestions, and peak and off-peak transportation. Each of these factors can change the perception of the respondent under which measure on transportation can be placed. 
Table 3. Level of influence of factors on efficiency and effectiveness

\begin{tabular}{|c|c|c|c|c|}
\hline \multirow{2}{*}{ Criteria } & \multirow{2}{*}{ Weights from AHP } & \multicolumn{3}{|c|}{ Affecting probability } \\
\hline & & for efficiency & for effectiveness & for both \\
\hline Transportation & 0.43 & 0.4 & 0.2 & 0.4 \\
\hline Accidents & 0.26 & 0 & 0 & 1 \\
\hline Packaging & 0.14 & 0.2 & 0.2 & 0.6 \\
\hline Method of storage & 0.08 & 0.4 & 0 & 0.6 \\
\hline Cleaning Process & 0.05 & 0.2 & 0.8 & 0 \\
\hline Sorting Process & 0.04 & 0.4 & 0.6 & 0 \\
\hline
\end{tabular}

All respondents have identified the prominent six factors affecting to both efficiency and effectiveness of reverse logistics in the soft drink industry in Sri Lanka. Out of five responses it depicts that cleaning process and sorting process mostly influence of effectiveness of reverse logistics, while accidents, a method of storage and packaging influence for both measures. Transportation seems to be the critical factor which it cannot be solely categorized on which measure it influence mostly. The least critical factors in the right corner have the most influence on the effectiveness of reverse logistics other than for both measures and efficiency.

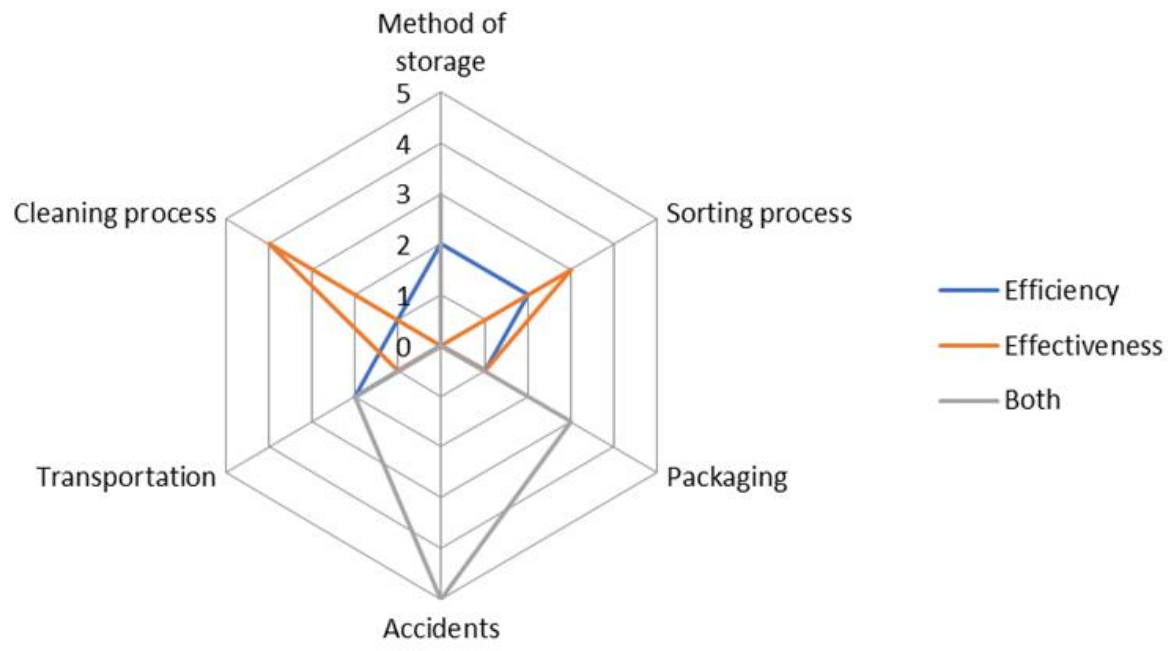

Figure 10. Impact scores of factors on efficiency and effectiveness

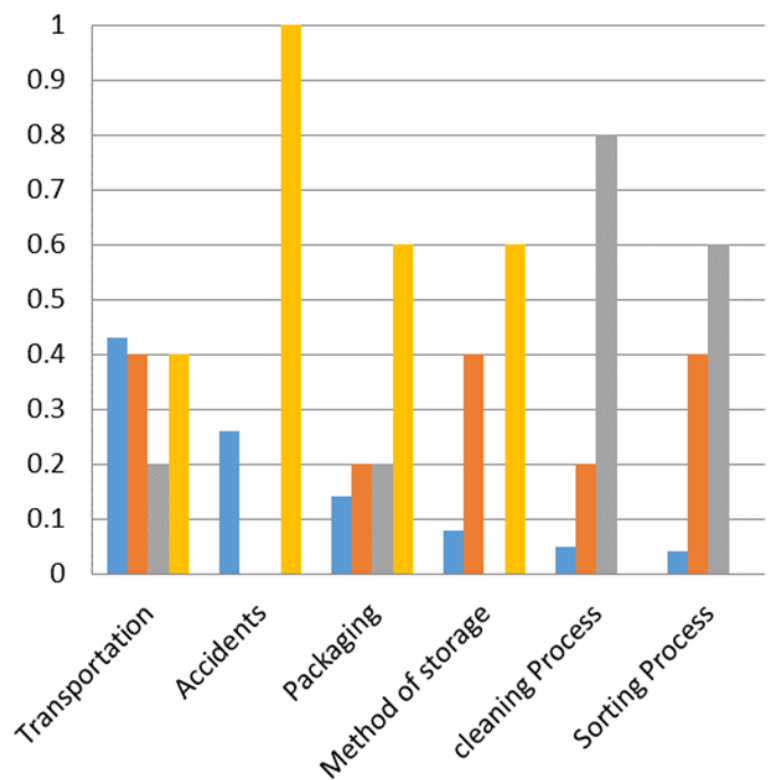

Weights from AHP

Affecting probability for efficiency

Affecting Probability for effectiveness

Affecting probability for both

Figure 11. Critical factors and the probability of impact on efficiency and effectiveness

The factors with higher weight show the criticality of that factor to reverse logistics while those are having a higher influence on both efficiency and effectiveness of the reverse logistics process. Apart from transportation, factors like accidents, packaging and the method of storage have a higher affecting probability for both measures (Figure 11). The 
affecting probability of two measures to the most critical factor, transportation seems to be distributed in a dispersed manner. Transportation affects the efficiency of reverse logistics with a probability of 0.4 , for effectiveness with a probability of 0.2 and for both with a probability of 0.4 out of the five responses received.

\section{Conclusion}

This paper demonstrated the most critical and prominent factors that can have severe impacts on the efficiency and effectiveness of reverse logistics of the soft drink industry. Analysis results showed several aspects of the current operating model and practices of the soft drink industry which can give a better understanding to any interested person in the soft drink industry. These research findings can give insights for the industry professionals on which factor they need to focus most to implement an efficient and effective reverse logistics channel. This emphasizes the importance of giving primary focus to the distribution channel even though it is outsourced. Manufacturers should audit the channel based upon the identified prominent factors and need to identify where the leakages happening. Even when taking major decisions like selecting a distributor or an agent for the distribution channel, the relevant factors from these prominent factors can be used and develop to key performance criteria as the base for the selection process.

All factors demonstrate the prominent factors affecting the efficiency and effectiveness of reverse logistics process. Out of the first four factors affect both efficiency and affectivity. Transportation has received low response rate that it affects for both efficiency and effectiveness of reverse logistics because, the factor transportation stands for a bigger scope covering numerous subfactors that can be included within it such as driving skill and behavior, vehicle condition, road condition, geographic features of the road, fuel efficiency of the vehicle, road congestions, peak off peak transportation etc. each of these factors can change the perception of the respondent under which measure transportation as a whole can be placed. Since transportation, accidents, packaging, and storage have a higher impact on both efficiency and effective measures these factors should be given specific consideration while in the operations. These factors will help to identify the correct root causes for the inefficiencies of the current practices and finally concentrating on these factors will give an opportunity for the soft drink industry players to successfully implement a sustainable green supply chain which reduces waste at each stage of its forwards and reverse logistics process.

Since transportation, accidents, packaging, and storage have a higher impact on both efficiency and effective measures these factors should be given specific consideration while in the operations. These factors will help identify the correct root causes for the inefficiencies of the current practices and finally concentrating on these factors will give an opportunity for the soft drink industry players to successfully implement a sustainable green supply chain which reduces waste at each stage of its forwards and reverse logistics process. As the current world is highly considerate on the sustainability aspects even plastic bottle manufacturers may consider these reusable containers production and the critical factors for the reverse logistics process when moving into this arena.

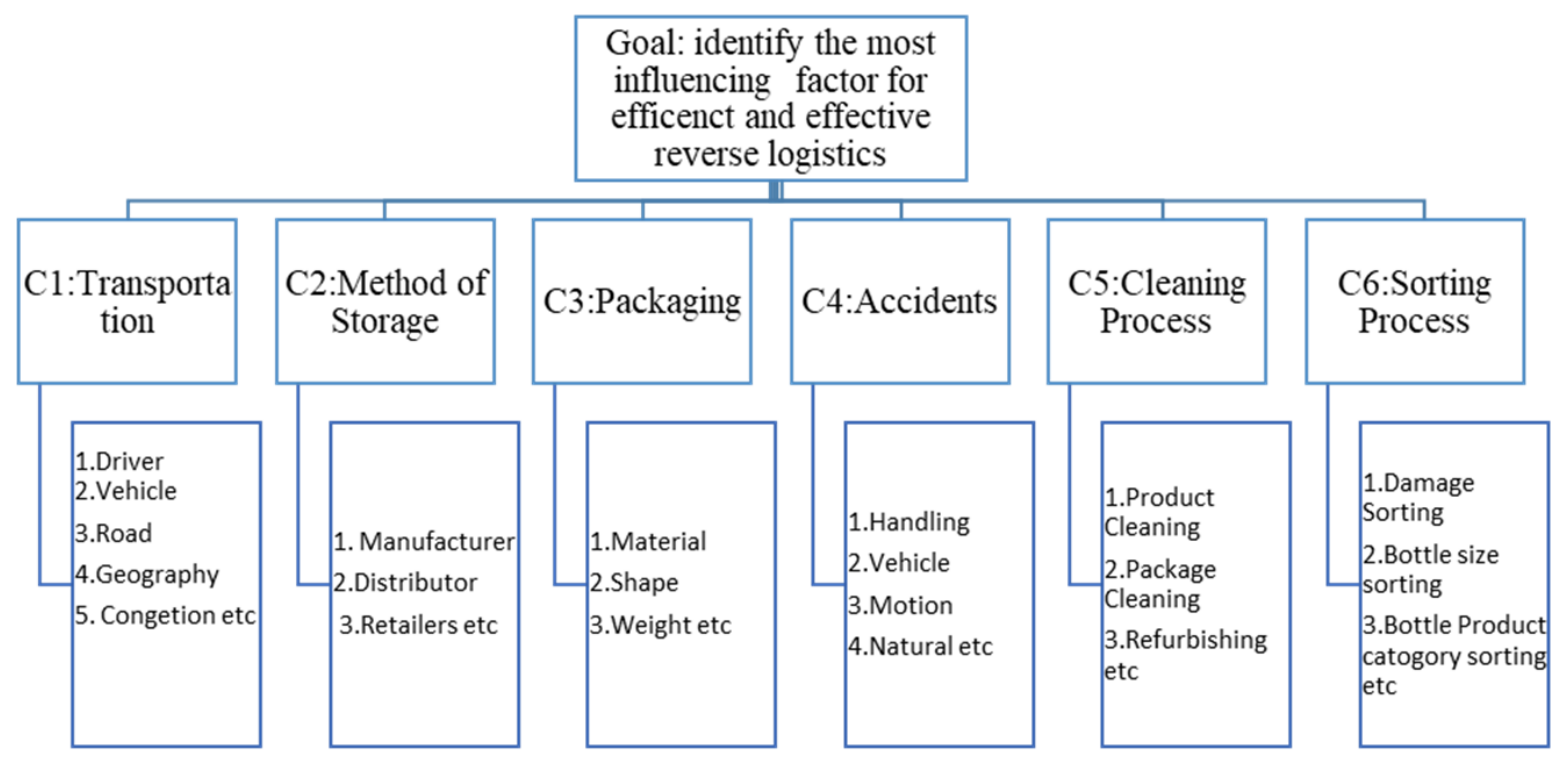

Figure 12. Potential future research areas

\section{Future research}

Research can be carried out for the different industry with the same set of glass bottles in Sri Lanka like pasteurized 
milk bottles, fruit drinks. This research will be a reference for those studies. This study was carried out on one level of the AHP. This same research can be carried out considering another level of AHP, considering subfactors under each prominent factor. The following Figure 12 shows an assumed illustration of the potential research area.

This research focuses on one reverse logistic activity (reuse) under packaging. This can be done for other logistics activities under packaging such as refurbishing, reclaim material, recycle and salvage for the same industry or for a different industry. Since this study focuses on efficient and effective measures to reverse logistics it is recommended considering another measure such as productivity, profitability or even the sustainability of reverse logistics channel.

\section{Acknowledgment}

We express our warm and sincere thanks to all industry participants who contributed in various ways for the data collection process.

\section{References}

Agrawal, S., Singh, R.K., Murtaza, Q., 2016. Prioritizing critical success factors for reverse logistics implementation using fuzzyTOPSIS methodology. Journal of Industrial Engineering International 12, 15-27.

Bahiraei, N., Panjehfouladgaran, H., Yusuff, R.M., 2015. Ranking of critical success factors in reverse logistics by TOPSIS. Proceedings of 2015 International Conference on Industrial Engineering and Operations Management, Dubai, United Arab Emirates.

Bloemhof-Ruwaard, J.M., Fleischmann, M., Van Nunen, J.A., 1999. Reviewing Distribution Issues in Reverse Logistics. In: Speranza M.G., Stähly P. (Eds) New Trends in Distribution Logistics. Lecture Notes in Economics and Mathematical Systems, vol 480. Springer, Berlin, Heidelberg.

Dekker, R., Fleischmann, M., Inderfurth, K., Van Wassenhove, L.N., 2004. Quantitative Models for Reverse Logistics Decision Making. In Reverse Logistics. In: Dekker R., Fleischmann M., Inderfurth K., Van Wassenhove L.N. (Eds) Reverse Logistics. Springer, Berlin, Heidelberg.

Dudubo, M., 2017. The reverse logistics of beverage containers-(a case study of Lagos, Nigeria). Master Thesis, Aalto University, Finland.

Fleischmann, M., Bloemhof-Ruwaard, J.M., Dekker, R., van der Laan, E., van Nunen, J.A.E.E., Van Wassenhove, L.N., 1997. Quantitative models for reverse logistics: A review. European Journal of Operational Research 103, 1-17.

Ganjali, M., Shirouyehzad, H., Shahin, A., 2016. Prioritizing critical success factors of reverse logistics in Hamgam Khodro Asia. Journal of Applied Research on Industrial Engineering 3, 39-48.

Guide, V.D.R., Wassenhove, L.N., 2003. Business Aspects of Closed-Loop Supply Chains: Exploring the Issues (Carnegie Mellon Business), Carnegie Mellon University Press Pittsburgh, USA.

Huscroft, J.R., Hazen, B.T., Hall, D.J., Skipper, J.B., Hanna, J.B., 2013. Reverse logistics: Past research, current management issues, and future directions. The International Journal of Logistics Management 24, 304-327.

Huscroft, J.R., 2010. The reverse logistics process in the supply chain and managing its implementation. Ph.D. Thesis, Auburn University, Alabama, USA.

Jian-Jun, W., Haozhe, Dale, S.R., Lisa, M.E., Scott J.G., 2017. A bibliometric analysis of reverse logistics research (1992-2015) and opportunities for future research. International Journal of Physical Distribution \& Logistics Management 47, 666-687.

Kim, J., 2009. Solving reverse logistics: Optimizing multi-echelon reverse network, Master Thesis, California Polytechnic State University, San Luis Obispo.

Kumarasiri, K., Arunathilake, S., 2016. Effective logistics process for the soft drink industry. Proceedings of the International Conference of Advances in ICT for Emerging Regions 2016, Negombo, Sri Lanka

Lee, J., McShane, H., Kozlowski, W., 2002. Critical issues in establishing a viable supply chain/reverse logistic management program. Proceedings of Conference Record 2002 IEEE International Symposium on Electronics and the Environment, San Francisco, USA

Mangla, S.K., Govindan, K., Luthra, S., 2016. Critical success factors for reverse logistics in Indian industries: A structural model. Journal of Cleaner Production 129, 608-621.

McLeod, F., Hickford, A., Maynard, S., Cherrett, T. and Allen, J., 2008. Developing innovative and more sustainable approaches to reverse logistics for the collection, recycling and disposal of waste products from urban centres: literature review and identification of opportunities. Project Report. University of Westminster and the University of Southampton. USA.

Ngadiman, I.N., Moeinaddini, M., Ghazali, J.B., Binti Roslan, N.F., 2016. Reverse logistics in food industries: A case study in Malaysia. International Journal of Supply Chain Management 5, 91-95.

Pokharel, S., Mutha, A., 2009. Perspectives in reverse logistics: A review. Resources, Conservation and Recycling 53, $175-182$.

Pumpinyo, S., Nitivattananon, V. 2014. Investigation of barriers and factors affecting the reverse logistics of waste management practice: A case study in Thailand. Sustainability 6, 7048-7062.

Reddy, D., 2011. A study on reverse logistics, Master Thesis, Mälardalens Högskola, Sweden.

Rogers, D.S., Tibben-Lembke, R.S., 1999. Going Backwards: Reverse Logistics Trends and Practices. Reverse Logistics Executive Council, University of Nevada, Reno.

Rogers, D.S., Tibben-Lembke, R.S., 2001. An examination of reverse logistics practices. Journal of Business Logistics 22, $129-148$.

Umer, M., Afzal, F., 2012. Analysis of reverse logistics in soft-drink bottling industry of Pakistan. Proceedings of the 2nd International Conference on Business Management, Lahore, Pakistan. 
Venkatesh, V., Bhattacharya, S., Sethi, M., Dua, S., 2015. Performance measurement of sustainable third party reverse logistics provider by data envelopment analysis: A case study of an Indian apparel manufacturing group. International Journal of Automation and Logistics 1, 273-293. 